\title{
Trends in basal cell carcinoma incidence rates: a 16-year retrospective study of a population in central Poland
}

\author{
Magdalena Ciążyńska ${ }^{1,2}$, Joanna Narbutt ${ }^{3}$, Anna Woźniacka4, Aleksandra Lesiak ${ }^{3}$ \\ ${ }^{1}$ Department of Proliferative Diseases, Regional Oncology Center, Lodz, Poland \\ 2Students' Faculty at the Department of Dermatology, Medical University of Lodz, Lodz, Poland \\ ${ }^{3}$ Department of Dermatology, Pediatric Dermatology and Dermatological Oncology, Medical University of Lodz, Lodz, Poland \\ ${ }^{4}$ Department of Dermatology and Venereology, Medical University of Lodz, Lodz, Poland
}

Adv Dermatol Allergol 2018; XXXV (1): 47-52

DOI: https://doi.org/10.5114/ada.2018.73164

\begin{abstract}
Introduction: Basal cell carcinoma (BCC) is the most commonly occurring cancer worldwide, and the overall incidence is still rising. Unfortunately, the cancer registry in Poland does not record BCC individually. Thus, the incidence of BCC in a defined population is unknown.

Aim: Analysis of incidence rates of primary BCC in central Poland during 16 years considering sex, site distribution and age to determine trends.

Material and methods: We retrospectively included all cases of BCC which were diagnosed and treated in the Department of Dermatology and Venereology, Medical University of Lodz, during the 16-year period from 1999 to 2015. Results: We recorded 945 BCCs occurring in 890 patients (504 females - 57\%, 386 males - 43\%). Patient's age was between 21 and 94. A distinct increase in BCC was observed after 1999, while after 2010 during the next 2-year period a slight decrease was noted. A statistically significant correlation was observed between histopathological types of BCC and the location of the lesions. The superficial type predominates on photoprotected areas, especially on the trunk, while the nodular type occurs mainly in facial areas. No statistically significant correlation was observed between histopathological types of BCC and sex. We found a significant increase in incidence for superficial BCC among middle-age patients, while the nodular type was observed more frequently among elderly subjects.

Conclusions: Basal cell carcinoma is quite common in Poland and predominantly develops in the facial area. In middle-age patients the most common is superficial BCC, while in elderly people the nodular type is most common. Based on our results we assume that there is a strong need to educate general physicians to enable them to diagnose BCC in the early stages.
\end{abstract}

Key words: anatomical location, basal cell carcinoma, nodular basal cell carcinoma, superficial basal cell carcinoma.

\section{Introduction}

Basal cell carcinoma (BCC) is a malignant epithelial neoplasm of the skin preferentially affecting patients with low skin phototype. The incidence of BCC is rising and it represents approximately $70-80 \%$ of all skin carcinomas $[1,2]$. Epidemiological data indicate that the overall incidence is growing 1-3\% annually. Basal cell carcinoma is not life threatening. Mortality rates associated with BCC are low $(<0.1 \%)$ but localized tissue invasion may induce considerable functional and cosmetic problems, especially because the majority of the lesions are located on the face $[3,4]$. Basal cell carcinoma is the most frequent skin cancer in the US population and also has strongly rising incidence in Europe including in Poland. With the increase in the incidence of BCC, even though mortality is relatively low, the morbidity and treatmentrelated cost represent a significant burden to the health care system. Chronic sun exposure is the most common risk factor for development of BCC. Both UVA and UVB contribute to BCC formation. It is one of the reasons why BCC occurs predominantly on the head and neck, although the anatomical site distribution is different for the histologic subtypes of BCC. Nodular BCC (nBCC) predominantly occurs on the head and neck, while superficial BCC (sBCC) mainly occurs on the trunk.

Address for correspondence: Aleksandra Lesiak MD, PhD, Department of Dermatology, Pediatric Dermatology and Dermatological Oncology, Medical University of Lodz, 1/5 Kniaziewicza St, 91-347 Lodz, Poland, fax: +48 426511072 ,

e-mail: aleksandra.lesiak@umed.lodz.pl

Received: 19.10 .2016 , accepted: 25.11.2016. 
Unfortunately, no reliable statistics on the incidence of BCC exist in Poland due to the lack of an efficient cancer registry system.

\section{Aim}

We analyzed incidence rates for primary BCC in central Poland in the period 1999-2015 by sex, site distribution and age to determine trends.

\section{Material and methods}

The study consists of 890 patients from the Department of Dermatology and Venereology, Medical University of Lodz, from 1999 to 2015, who were diagnosed and treated for BCC. In all cases the diagnoses of BCC were confirmed by histological examinations. All analyzed data (localization, age, gender, BCC type) were obtained from medical records. The groups of patient cases were divided into 5 -year intervals for further analysis. The results were analyzed statistically by the $\chi^{2}$ test, with $p<0.05$ considered as being significant.

\section{Results}

We recorded 945 BCCs occurring in 890 patients (504 females $-57 \%$, 386 males $-43 \%$ ). The patients were recorded at age between 21-94 years (mean age for both sex was 66.15 years). Average age for females was 66.20 years, while for males it was 66.06 years. The number of patients for each sex in the successive years is presented in Figure 1. In 51 patients multiple BCCs were diagnosed. The highest number of carcinomas in a single patient was 4 . In 4 out of 51 patients there were 3 carcinomas while in 43 patients there were 2 BCCs.

The global distribution of histological subtypes confirmed the predominance of the nodular type - nBCC (659 cases $-69.74 \%$ of 945 ). The other subtypes of BCC

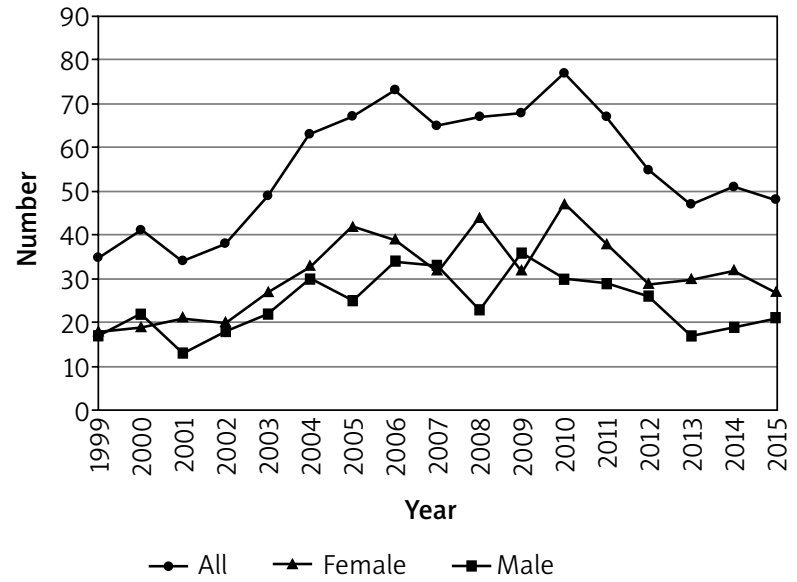

Figure 1. Annual number of cases in Lodz with diagnosed BCC between 1999 and $2015(n=945)$ were: SBCC $-21.80 \%$ (206 cases), BCC infiltrative $-6.73 \%$ (64 cases), BCC pigmented $-0.63 \%$ (6 cases), BCC ulcer - 0.53\% (5 cases), BCC adenoid - 0.32\% (3 cases) and BCC cystic $-0.21 \%$ (2 cases). The number of various BCC subtypes in the successive years is presented in Figure 2.

The information about BCC distribution was collected in 739 cases. In the vast majority of cases (351, $47.50 \%)$ BCC was located on the face, especially on the nose $(32.76 \%)$. Other locations on the face are as follows: forehead $(24.14 \%)$, cheek (18.53\%), temple (12.50\%), earlobe $(6.03 \%)$, chin $(2.59 \%)$, eyehole (1.72\%), nasolabial folds (1.72\%). The second most common location was the trunk, with 224 (30.31\%) cases. In 59 (7.99\%) cases BCC occurred on a lower limb, in 47 (6.20\%) cases on an upper limb, in 35 (4.74\%) cases on the neck. The least common location was the scalp (23 cases $-3.11 \%$ ).

Analyzing BCC distribution in regard to sex we revealed that the most frequent location both in males and females was the face, with 199 (48.07\%) cases for females and 152 (46.77\%) cases for males. For females the next most common location was the trunk, with 128 (30.92\%) cases, the lower limb, with 35 (8.45\%) cases, and the upper limb and neck - both with 19 (4.59\%) cases. The least common BCC location in females was the scalp, with 14 (3.38\%) cases. For males the second most frequent location of BCC was the trunk, with 96 (29.54\%) cases, the third one the upper limb (28 cases $-8.62 \%$ ). The fourth one was the lower limb, with 24 (7.38\%) cases, and the fifth was the neck, with 16 (3.86\%) cases. Only 9 cases were registered on the scalp surface (2.77\%).

Nodular BCCs were the most frequent BCC type for both males and females (659-69.74\% of all cases, 290 cases in men $-69.88 \%$ and 369 cases in women $69.62 \%)$. No statistically significant correlation was observed between sex of the patients and histopathological types of BCC ( $\mathrm{nBCC} p=0.96$; sBCC $p=0.44$; BCC infiltrans $p=0.63)$. The rare $B C C$ subtypes were not present-

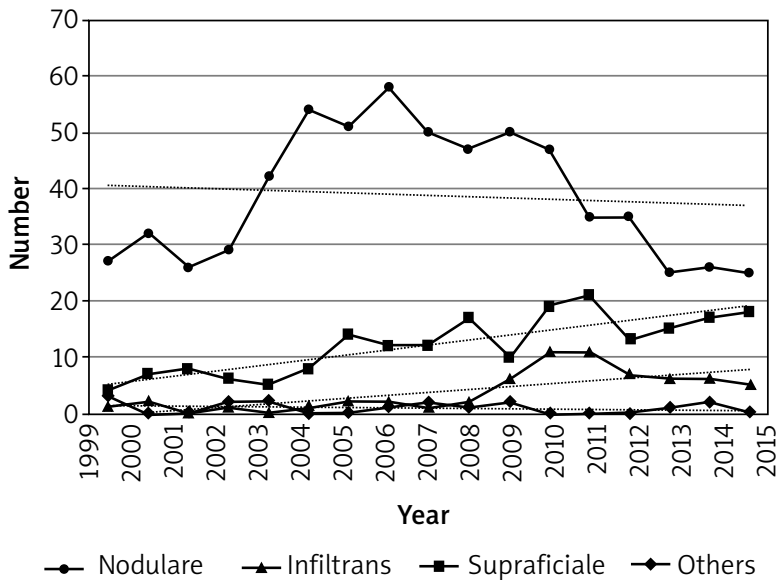

Figure 2. Occurrence of various BCC types between 1999 and $2015(n=945)$ 
ed in the results due to the low number of occurrences for those subsets.

A statistically significant correlation was observed between histopathological subtypes of BCC and the location of the lesions $(p<0.0001)$. The superficial type predominates on photoprotected areas, especially on the trunk, while the nodular type occurs mainly on facial areas.

Age-specific incidence rates for BCC histological subtypes in males and females are presented in Figure 3. The patients in the age group between 35 and 45 years present dominance of sBCC over nBCC $(p<0.05)$. In contrast, nBCC was most prevalent in older patients (group over 75 years old; $p=0.036$ ).

A significant correlation between particular age and sex of patients was demonstrated. Male dominance was observed for patients between 60 and 65 years old ( $p=$ 0.046), while a higher number of female patients were in the age between 85 and 90 years old $(p=0.041)$. The most numerous BCC group, containing 142 cases ( $73 \mathrm{fe}-$ males; 69 males), concerns patients between 70 and 75 years old. The smallest group included patients below 25 years (3 cases), and the youngest BCC case was diagnosed in a 21-year-old patient (Figure 4).

Site distribution of BCC in particular age groups is presented in Figure 5. In our study group a significant difference between the site distribution and age was observed. We revealed that the majority of lesions localized on the trunk occurred in younger patients. A statistically significant difference was observed for patients aged between 35 and $40(p=0.0036)$ and for patients aged between 45 and 50 ( $p=0.0036$; Table 1).

\section{Discussion}

Basal cell carcinoma is considered to be the most common skin malignancy. Based on the previously published data BCCs comprise about $80 \%$ of all non-melanoma skin cancers (NMSC) and their incidence continues to rise, doubling every 25 years. This could be caused by increased exposure to UV light and ozone depletion in various parts of the world due to environmental and industrial pollution $[5,6]$. Despite the high prevalence of these tumors, there is a lack of reliable epidemiological data in most European countries, including Poland [5]. Lesiak et al. [7] confirmed those observations in a report during the 7-year period 2000-2006 by retrospective analysis. This increasing trend was also recorded in our study for all age groups in the analyzed period during the 16-year period between 1999 and 2015. The systematic increase was observed up to the year of 2010, whereas during the next 2-year period a slight decrease was noted.

Although in some literature data the BCC distribution is two times higher for males than women [8-11], in our study we observed female predominance over men. However, there was no statistically significant difference between men and women.

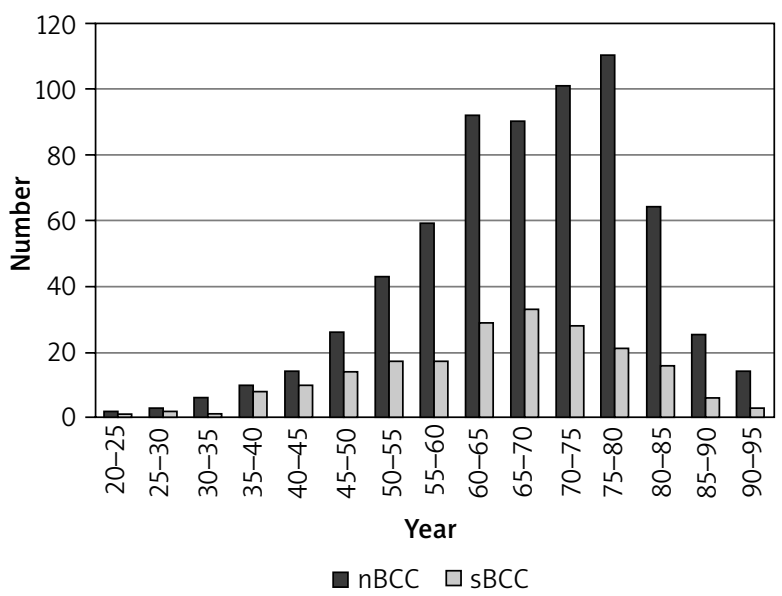

Figure 3. Age-specific incidence rates for BCC subtypes $(n=865)$

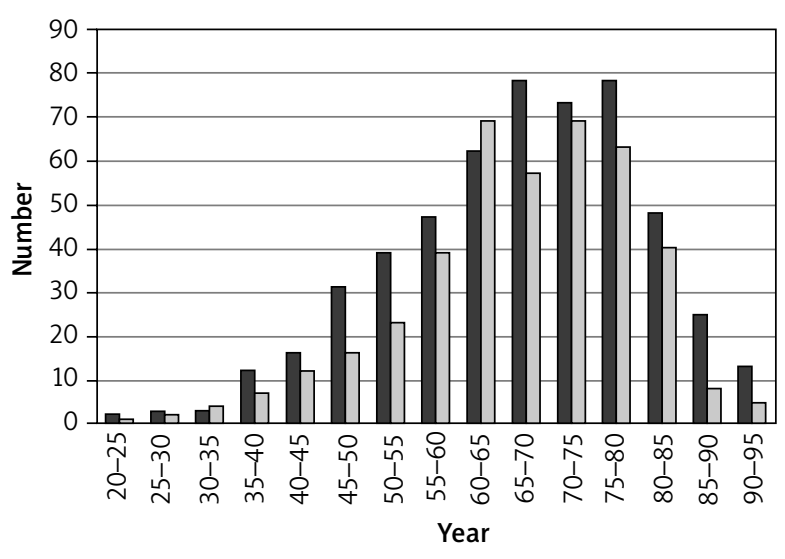

- Female $\square$ Male

Figure 4. Age-specific incidence rates in relation to sex $(n=945)$

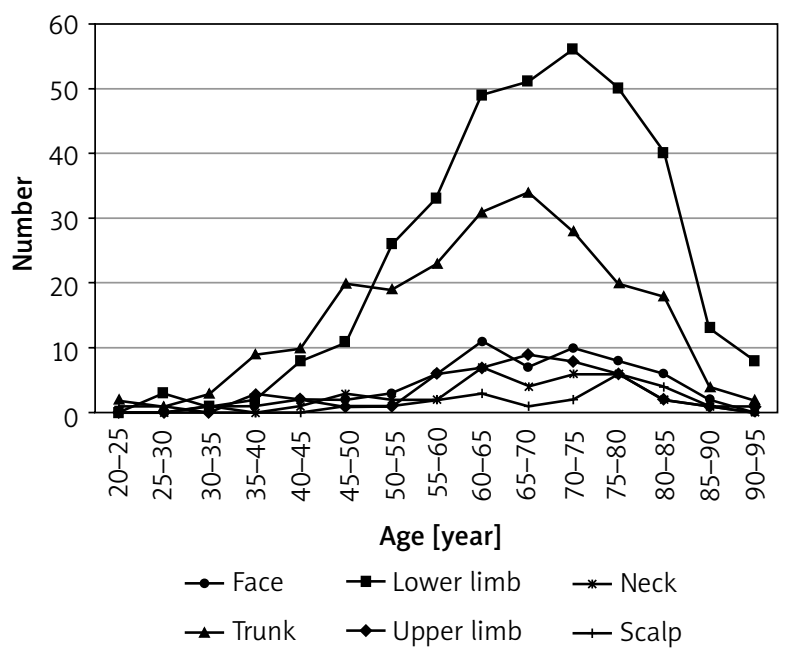

Figure 5. Site distribution for age-specific incidence rates $(n=739)$ 
Table 1. Basal cell carcinoma localization in regard to gender

\begin{tabular}{|c|c|c|c|c|c|c|c|c|}
\hline \multirow[t]{2}{*}{ Gender } & \multirow[t]{2}{*}{ Localization } & \multicolumn{2}{|c|}{ Nodular } & \multicolumn{2}{|c|}{ Superficial } & \multicolumn{2}{|c|}{ Other } & \multirow[t]{2}{*}{ Total } \\
\hline & & $n$ & $\%$ & $n$ & $\%$ & $n$ & $\%$ & \\
\hline \multirow[t]{8}{*}{ Males } & Face & 122 & 53.98 & 14 & 20.29 & 16 & 53.33 & 152 \\
\hline & Trunk & 49 & 21.68 & 41 & 59.42 & 6 & 20.00 & 96 \\
\hline & Upper limb & 19 & 8.41 & 5 & 7.25 & 4 & 13.33 & 28 \\
\hline & Lower limb & 16 & 7.08 & 7 & 10.14 & 1 & 3.33 & 24 \\
\hline & Scalp & 6 & 2.65 & 0 & 0.00 & 3 & 10.00 & 9 \\
\hline & Neck & 14 & 6.19 & 2 & 2.90 & 0 & 0.00 & 16 \\
\hline & Not determined & 64 & & 16 & & 10 & & 90 \\
\hline & All & 290 & & 85 & & 40 & & 415 \\
\hline \multirow[t]{8}{*}{ Females } & Face & 166 & 58.66 & 14 & 14.74 & 19 & 52.78 & 199 \\
\hline & Trunk & 53 & 18.73 & 63 & 66.32 & 12 & 33.33 & 128 \\
\hline & Upper limb & 12 & 4.24 & 5 & 5.26 & 2 & 5.56 & 19 \\
\hline & Lower limb & 27 & 9.54 & 7 & 7.37 & 1 & 2.78 & 35 \\
\hline & Scalp & 10 & 3.53 & 3 & 3.16 & 1 & 2.78 & 14 \\
\hline & Neck & 15 & 5.30 & 3 & 3.16 & 1 & 2.78 & 19 \\
\hline & Not determined & 86 & & 26 & & 4 & & 116 \\
\hline & All & 369 & & 121 & & 40 & & 530 \\
\hline$\Sigma$ & & & & & & & & 945 \\
\hline
\end{tabular}

A similar observation was noted in other studies [7, 12-17]. Data reported by the Polish Central Statistical Office (GUS - Gtówny Urząd Statystyczny) in 2015 show that women in the region of central Poland (Lodz district) live 9 years and 1 month longer than men [18]. Most studies indicate a higher risk for BCC development in the elderly and that fact could explain this proportion in the examined cohort.

The great majority of patients with BCC (95\%) are noted to be between 40 and 79 years of age $[7,17,19]$. In our study the most numerous group of cases was between 70 and 75 (142 cases). Basal cell carcinoma is relatively uncommon under the age of 40 and is rather rare in adolescents. This is confirmed in our study, with only a few patients under 25 years old and more than $90 \%$ of patients aged above 40 years old. Most studies present an increase in the number of cases in younger woman, whereas in our group this was not observed. The average age of female with BCC in 1999 was 60.56 years (based on 18 cases) while in 2015 it was 69.69 (based on 28 cases). A similar result was noted for males [20-22].

The most frequent histological subtype of BCC was nodular (69.74\%) followed by superficial type (21.80\%). The findings are consistent with the observations performed by others $[7,13,15]$. On the other hand, a series from France presents the opposite observation, in which the superficial type was in the majority. There was also no significant correlation between histopathological subtype of BCCs and sex of the patients, and this confirms the similar facts reported in other studies $[7,16]$.
In the present study most of the SBCCs were reported in the younger group, while the nodular subtype was more characteristic for elderly people. In contrast to the current results, the previous study performed in the same region of central Poland during the years 2000 and 2006 did not reveal any significant correlation between histopathological subtype of BCCs and age of patients [7]. The predominance of sBCC over nBCC in the younger group of cases has been observed worldwide in various literature $[9,15]$.

The site distribution in our population is in concordance with the literature. The highest percentage (47\%) of all BCC lesion cases were located on the face, followed by the trunk, lower and upper limb, neck and hair-free skin. The trends observed in our population could be confirmed in other studies [17, 23]. In recent years it has been observed that more and more BCCs develop on the trunk, while the number of BCC lesions located on the face has decreased. Similar trends are described by others $[17,23]$. The proportional increase in truncal BCC in our population could reflect changing habits with regards to sun exposure. Healthy lifestyle and recent fashion could contribute to an increase of exposure to sunlight and UV radiation. On the other hand, increased care of skin that leads to extensive usage of creams and cosmetics contributes to face protection. Those factors could keep the number of BCC cases at the same level annually.

The detailed analysis of BCC distribution on the face area indicates that the nose is the most common ana- 
tomical site followed by the forehead, cheek, temple, ear, chin, eyehole and nasolabial fold. These results were in line with other studies that also report the nose to be the most commonly involved site for BCC [24-26]. The BCC lesions could develop on the places extensively exposed to sun as well as on sites usually protected from sun exposure. The etiology between BCC subtypes differs, as described by McCormack et al. [27]. Both intermittent and intense sun exposure are the leading risk factors for BCC [28]. Superficial BCC occurs predominantly on the trunk. Due to the fact that the trunk is not continuously exposed to sunlight, intermittent sun exposure could be particularly important in the etiology of this subset of BCC. On the other hand, nodular BCC most frequently occurs in the head or neck $[13,14]$. Those data have been confirmed by our research, and $64 \%$ of nBCCs are located on sites with high exposure to UV radiation (head and neck), while $66 \%$ of sBCCs are located on the trunk a place usually protected from light.

\section{Conclusions}

Basal cell carcinoma is quite common in Poland. Clinical characteristics of BCC in central Poland patients have similarities with other countries in Europe. The present population-based study provides subtype-specific incidence rates for BCC with predominance in the facial area. We found an increase in incidence among middle-age patients for sBCC, while nBCC occurs more frequently in elderly people. An alarming acceleration in BCC was observed after 1999 in our region and was increasing annually. Besides emphasizing the need for effective primary preventative skin cancer strategies, these results are a warning to our society. Governments and health professionals need to respond to this "BCC epidemic" to decrease BCC rates in the future. Also it would be advisable to perform tutorials for general practitioners in order enable them to diagnose BCC in the early stages.

\section{Acknowledgments}

The study was funded by the National Center of Science grant no. 2012/05/B/NZ5/01885 and the Medical University of Lodz, project no. 503/5-064-01/503-01 and 503/1-152-01/503-01.

\section{Conflict of interest}

The authors declare no conflict of interest.

\section{References}

1. Pabiańczyk R, Cieślik K, Tuleja T. Metody leczenia raka podstawnokomórkowego skóry. Chir Pol 2011; 13: 48-58.
2. Dacosta Byfield S, Chen D, Yim YM, Reyes C. Age distribution of patients with advanced non-melanoma skin cancer in the United States. Arch Dermatol Res 2013; 305: 845-50.

3. Lewis KG, Weinstock MA. Trends in nonmelanoma skin cancer mortality rates in the United States, 1969 through 2000. J Invest Dermatol 2007; 127: 2323-72.

4. Jensen AO, Bautz A, Olesen AB, et al. Mortality in Danish patients with nonmelanoma skin cancer, 1978-2001. Br J Dermatol 2008; 159: 419-25.

5. Murphy M, Mabruk M, Lenane $P$, et al. Comparison of the expression of p53, p21, Bax and the induction of apoptosis between patients with basal cell carcinoma and normal controls in response to ultraviolet irradiation. J Clin Pathol 2002; 55: 829-33.

6. Kauvar AN, Cronin T, Roenigk R, et al. Consensus for nonmelanoma skin cancer treatment: basal cell carcinoma, including a cost analysis of treatment methods. American Society for Dermatologic Surgery 2015; 0: 1-22.

7. Lesiak A, Slowik-Rylska M, Rogowski-Tylman M, et al. Risk factors in Central Poland for the development of superficial and nodular basal cell carcinomas. Arch Med Sci 2010; 6: 270-5.

8. Flohil SC, Seubring I, van Rossum MM, et al. Trends in basalcell carcinoma incidence rates: a 37-year Dutch observational study. J Invest Dermatol 2013; 133: 913-8.

9. Raasch BA, Buettner PG, Garbe C. Basalcell carcinoma: histological classification and body-site distribution. Br J Dermatol 2006; 155: 401-7.

10. Ceylan C, Oztürk G, Alper S. Non-melanoma skin cancers between the years of 1990 and 1999 in Izmir, Turkey: demographic and clinicopathological characteristics. J Dermatol 2003; 30: 123-31.

11. Coups EJ, Manne SL, Heckman CJ. Multiple skin cancer risk behaviors in the U.S. population. Am J Prev Med 2008; 34: 87-93.

12. Cho S, Kim MH, Whang KK, et al. Clinical and histopathological characteristics of basal cell carcinoma in Korean patients. J Dermatol 1999; 26: 494-501.

13. Scrivener Y, Grosshans E, Cribier B. Variations of basal cell carcinomas according to gender, age, location and histopathological subtype. Br J Dermatol 2002; 147: $41-7$.

14. Czarnecki D, Collins N, Meehan C, et al. Basal-cell carcinoma in temperate and tropical Australia. Int J Cancer 1992; 50 : 874-5.

15. Bastiaens MT, Hoefnagel JJ, Bruijn JA, et al. Differences in age, site distribution, and sex between nodular and superficial basal cell carcinoma indicate different types of tumors. J Invest Dermatol 1998; 110: 880-4.

16. Bernard P, Dupuy A, Sasco A, et al. Basal cell carcinomas and actinic keratosis seen in dermatological practice in France: a cross-sectional survey. Dermatology 2008; 216: 194-9.

17. Deja M, Teresiak E, Buczyńska-Górna M, et al. Analysis of the appearance of different histological types of basal cell carcinoma, localization of the lesions, the age and sex of patients. Postep Derm Alergol 2004; 21: 231-9.

18. Przeciętne trwanie życia w 2015 r. według województw; Główny Urząd Statystyczny - Portal informacyjny (http://stat.gov.pl/), Accessed September 30, 2016.

19. Gürsan N, Kabalar E, Yıldırım Ü. Bazal hücreli karsi-nomların klinik ve histopatolojik degerlendirilmesi. Turk J Dermatopathol 2000; 9: 23-8.

20. de Vries E, Louwman M, Bastiaens M, et al. Rapid and continuous increases in incidence rates of basal cell carcinoma 
in the southeast Netherlands since 1973. J Invest Dermatol 2004; 123: 634-8.

21. Bath-Hextall F, Leonardi-Bee J, Smith C, et al. Trends in incidence of skin basal cell carcinoma. Additional evidence from a UK primary care database study. Int I Cancer 2007; 121: 2105-8.

22. Staples MP, Elwood M, Burton RC, et al. Non-melanoma skin cancer in Australia: the 2002 national survey and trends since 1985. Med J Aust 2006; 184: 6-10.

23. Ferreira FR, Pevide Bda, C, Rodriques RF, et al. Differences in age and topographic distribution of the different histological subtypes of basal cell carcinoma, Taubaté (SP), Brazil. An Bras Dermatol 2013; 88: 726-30.

24. Tiftikcioğlu YO, Karaaslan O, Aksoy HM, et al. Basal cell carcinoma in Turkey. J Dermatol 2006; 33: 91-5.

25. Janjua OS, Qureshi SM. Basal cell carcinoma of the head and neck region: an analysis of 171 cases. J Skin Cancer 2012; 2012: 943472.

26. Demirseren DD, Ceran C, Aksam B, et al. Basal cell carcinoma of the head and neck region: a retrospective analysis of completely excised 331 cases. J Skin Cancer 2014; 2014: 858636.

27. McCormack CJ, Kelly JW, Dorevith AP. Differences in age and body site distribution of histological subtypes of basal cell carcinoma. A possible indicator of different causes. Arch Dermatol 1997; 133: 593-6.

28. Kricker A, Amstrong BK, English DR, Heenan PJ, Does intermittent sun exposure cause basal cell carcinoma? A casecontrol study in Western Australia. Int I Cancer 1995; 60: 489-94. 